NOTICE: this is the author's version of a work that was accepted for publication in Journal of Labor Economics. Changes resulting from the publishing process, such as peer review, editing, corrections, structural formatting, and other quality control mechanisms may not be reflected in this document. Changes may have been made to this work since it was submitted for publication. A definitive version was subsequently published in Journal of Labor Economics, Vol. 37, No. 1, January 2019, https://doi.org/10.1086/698897 


\title{
More Education, Less Volatility? The Effect of Education on Earnings Volatility over the Life Cycle
}

\author{
Judith M Delaney*1 and Paul J Devereux ${ }^{* 2}$ \\ ${ }^{1}$ Economic and Social Research Institute, University College London \\ (UCL) and Institute of Labor Economcis (IZA) \\ ${ }^{2}$ University College Dublin, CEPR, and IZA
}

\begin{abstract}
Much evidence suggests that having more education leads to higher earnings in the labor market. However, there is little evidence about whether having more education causes employees to experience lower earnings volatility or shelters them from the adverse effects of recessions. We use a large British administrative panel data set to study the impact of the 1972 increase in compulsory schooling on earnings volatility over the life cycle. Our estimates suggest that men exposed to the law change subsequently had lower earnings variability and less pro-cyclical earnings. However, there is little evidence that education affects earnings volatility of older men.
\end{abstract}

*Delaney: Economic and Social Research Institute, Whitaker Square, Sir John Rogerson's Quay, Dublin 2, Ireland. Email: judithmdelaney@gmail.com. Devereux: University College Dublin, Belfield, Dublin 4, Ireland. Email: devereux@ucd.ie. Thanks to the UK data service for kindly allowing access to the data. Delaney gratefully acknowledges financial support from the ESRC which was received while undertaking part of this research. We also thank seminar participants at University College London and at the 2016 Irish Economic Association in Galway. This paper forms a chapter of Delaney's thesis which was completed at University College London. Delaney wishes to thank her advisors, Sir Richard Blundell and Eric French, for helpful comments. 


\section{Introduction}

Earnings volatility is a feature of modern labour markets as individual workers are subject to wage and hours variation. In the absence of full insurance against labour market adversities, volatility can have large effects on the welfare of individuals (Banks et al. (2001), French (2005), Blundell et al. (2008), Low et al. (2010), Heathcote et al. (2014)). Little is known about whether investments in education provide shelter against these economic uncertainties. We study how a compulsory schooling law that increased educational attainment affected several measures of earnings volatility faced by employees.

Our focus is on the variation over time in earnings for individual workers and we use three different measures of earnings volatility - earnings variability (the individual-level standard deviation of earnings within 5-year periods), the degree of earnings cyclicality, and the probability of experiencing a pay cut over a 5-year period. While these do not capture all aspects of earnings experiences (such as variation over time in average earnings across 5-year periods), together they paint a picture of how exposure to the law affects individual-level earnings volatility.

Persons with more education may have higher ability and differ in other unobserved ways that lead them to have less or more earnings volatility independent of their educational attainment. Generally, the empirical work in this area has documented associations between educational attainment and earnings volatility rather than sought to estimate causal effects 11 There are some exceptions: Although not the central focus of her paper, Chen (2008) uses U.S. data to estimate the effect of education on the transitory component of earnings using a parametric selection model. Contemporaneous to our research, Liu et al. (2015) use compulsory schooling changes in Norway to estimate how education affects the transitory and persistent component of earnings. Our focus is different in that we study simple direct measures of earnings volatility experienced by employed individ-

\footnotetext{
${ }^{1}$ Using the PSID, Meghir and Pistaferri (2004) find a u-shaped pattern with high school graduates having lower earnings volatility than high school dropouts but higher than college graduates, while, using Norwegian data, Blundell et al. (2015) find that the interaction of earnings volatility and the life cycle differs by education. There is also a substantial theoretical literature that directly models the inherent risk in education, for example, Altonji (1993), Keane and Wolpin (1997), Johnson (2013), Athreya and Eberly (2013), Ionescu and Simpson (2015) and Delaney (2017).
} 
uals. In fact, to our knowledge, this is the first paper that studies the direct causal effect of education on these particular measures. Additionally, we contribute to the literature by studying a highly cyclical labour market up to and including the great recession.

Using a large panel dataset, we estimate a regression discontinuity design based on the 1972 change in compulsory schooling in the UK that increased the minimum school leaving age from 15 to 16 . Our estimates suggest that an additional year of education leads to lower earnings variability (a reduced 5-year standard deviation of log earnings of about 0.01 , about $10 \%$ of the mean standard deviation), a decreased probability of receiving a pay cut of about 3.5 percentage points, and to a lower level of earnings cyclicality. However, there is little evidence that education affects earnings variability for older men. A recent survey paper highlights that education leads to large benefits in terms of wages, health, employment, voting behaviour, crime, teenage pregnancy, decision making and in many other dimensions (Oreopoulos and Salvanes, 2011); we show an additional channel through which education may lead to welfare gains for individuals lower earnings volatility.

There are many reasons to expect that earnings volatility may be influenced by education level. When searching for jobs, more educated workers may be more effective (have greater search capital) and may achieve better job matches with lower subsequent earnings volatility (Mincer, 1991). More educated workers are likely to be more mobile geographically and hence able to move region in order to reduce the effects of local shocks (Machin et al. 2012). Finally, more educated workers may be quicker to adapt to technological advances and/or have skills that are complementary to technology, and so may have less variable earnings in times of structural change within the economy. While these factors tend to imply lower earnings volatility for more educated workers, there are other factors that suggest the opposite. More education typically comes with the likelihood of greater specialisation that may make the worker more exposed to specific shocks. The minimum wage may also lead to less volatility for those with lower education since it provides a lower bound on wages. As such, whether greater education lowers earnings volatility of employed workers is an empirical question which we attempt to answer in this paper. 


\section{Data}

The New Earnings Survey Panel Dataset (NESPD) is a large administrative dataset covering the period from 1975. It follows a random sample of $1 \%$ of the British population whose national insurance number ends in a certain pair of digits. The survey refers to a specific week in April each year and excludes the self-employed. Because the survey uses national insurance numbers, the attrition rate is very low since if an individual temporarily drops out of the labour market, becomes unemployed, self-employed or changes job, they will tend to be picked up again once they become employed. The main advantage of the dataset, apart from the large sample sizes, is that the data are very accurate. Employers are obliged by law to fill out the employee information and thus there is less measurement error or non-response than is typically the case in household surveys. ${ }^{2}$ Also, the long period of time covered by the dataset makes it ideal for estimating cyclical effects. The data span the recessions of the early 80 s, early 90 s and the recent 'Great Recession'.

If an individual is not in the data in a particular year, we do not observe whether this is due to non-employment, self-employment, or to some form of non-response. Up to 2003, men who changed jobs between February and April are likely to be missing as the survey forms were sent out to employers in February but employers are asked about their employees in a specific week in April. Additionally, persons who terminate or begin jobs during the reference week in April are missed. On average, during their time in the NESPD, about $33 \%$ of observations are missing in any particular year. Consistent with most of the returns to education literature, our analysis is conditional on employment as there is no way to credibly impute earnings for persons who are missing from the survey. Later, we show that there is no evidence that the probability of being missing from the survey is related to the education reform. Furthermore, when studying the standard deviation of weekly earnings, we show that our estimates are robust to requiring differing numbers of non-missing observations in each of the 5-year periods we study.

\footnotetext{
${ }^{2}$ One concern is that since the survey is based on payroll records it only samples those who earn enough to be above the PAYE threshold; however Devereux and Hart (2010) have shown that the exclusion of those who earn very low earnings is not important.
} 
Our measure of earnings is the log of weekly pay including overtime. Because of the difficult issues involved in dealing with non-participation of women in the labour market, we focus our analysis on males. We exclude those individuals whose pay was affected by absence and limit the sample to employed men aged between 20 and 60 to reduce selection effects that typically occur at the beginning and end of the life cycle $\mathrm{S}^{3}$ Because the compulsory schooling law changed for the 1957 cohort, we only include those born between 1947 and 1967 and, in our primary analyses, we study cohorts born between 1952 and 1962.

For survey years prior to 2004, the age variable in the survey refers to age as at January 1st. Therefore, we calculate year of birth as year - age - 1. From 2004 onwards the age variable refers to age at the time of survey which implies that assigning year of birth to be equal to year - age - 1 will only be correct roughly two thirds of the time. We contacted the UK's Office for National Statistics (ONS) who kindly provided us with the actual year of birth of individuals from 2004 onwards. Since the first persons affected by the law change were born in September 1957, this implies that our 1957 cohort includes both treated and untreated individuals. Therefore, we drop this cohort in our main analyses but also report estimates where we set the law variable equal to $1 / 3$ for persons born in 1957. We do know, however, that all persons in our 1956 cohort were untreated and all persons in our 1958 cohort were treated $4^{4}$

Persons born in 1962 are recorded as aged 20 in the 1983 survey year. 1983 is, therefore, the first survey year in which all persons born between 1952 and 1962 are potentially in our sample. Likewise, persons born in 1952 are aged 60 in 2013 so this is the last year in which all persons born between 1952 and 1962 are potentially in our sample. For this reason, we restrict our analysis to the 1983 to 2013 years of the NESPD. If we were to use earlier survey years, some cohorts would not be present in all years and our estimates could be affected by year effects arising from periods of very high or low

\footnotetext{
${ }^{3}$ Since we are interested in the effect of an extra year of school at age 15 , by age 20 we expect that the complier group will mostly be in the labour market.

${ }^{4}$ We have information on school cohort from 2004 but not for earlier survey years. Because most of our data are pre-2004, we use calendar year cohort in our analysis. This affects the efficiency of our estimates but not consistency.
} 
earnings volatility.

We deflate the weekly pay measure to 2013 prices using the Retail Price Index (RPI) for April and trim the bottom and top $0.5 \%$ of earnings each year to eliminate serious outliers $5^{5}$ In addition, we drop observations with sex or age discrepancies. Finally, we drop those with hours of work less than 1 hour per week. The resulting sample has $1,104,104$ observations. The unemployment rate we use refers to the claimant count rate for the April corresponding to the survey year. When conducting regional analysis we use the corresponding regional unemployment rate.

Table 1 displays the descriptive statistics for our broad sample that includes cohorts from 1947 to 1967 and our primary sample that includes just the 1952 to 1962 birth cohorts. The "Law Affected" variable is 1 if the person was subject to the higher compulsory schooling age of 16 and zero otherwise.

Table 1: Descriptive Statistics for Males NESPD 1983-2013

\begin{tabular}{cccc}
\hline \hline Variable & Observations & Mean & Standard Deviation \\
\hline Cohorts = 1947-1967 & & & \\
Year & $1,104,104$ & 1997.23 & 8.48 \\
Cohort & $1,104,104$ & 1957.37 & 6.08 \\
Age & $1,104,104$ & 38.95 & 9.57 \\
Log Weekly Pay & $1,104,104$ & 6.33 & 0.514 \\
Law Affected & $1,104,104$ & 0.536 & 0.499
\end{tabular}

\section{Cohorts $=1952-1962$}

\begin{tabular}{cccc} 
Year & 574,498 & 1997.15 & 8.76 \\
Cohort & 574,498 & 1957.25 & 3.33 \\
Age & 574,498 & 38.99 & 9.35 \\
Weekly Pay & 574,498 & 6.34 & 0.512 \\
Affected & 574,498 & 0.537 & 0.499 \\
\hline
\end{tabular}

Note: Observations refers to number of person-year observations.

\footnotetext{
${ }^{5}$ The RPI is the only price index in the UK which covers the sample period.
} 


\section{Earnings Volatility Measures}

In this section, we discuss the rationale for each measure and how exactly we implement it in our data. We can only consider earnings of employed men as we have no information on earnings for the non-employed or self-employed.

Earnings Variability: Our primary measure of earnings volatility is earnings variability and we measure it using the standard deviation of $\log ($ weekly pay). Since education may have differing effects on earnings variability at different ages, we construct the standard deviation for each person at each age using the variation in $\log$ (weekly pay) over the five year period centred on that age. To help describe our basic approach, we start with the simple statistical model:

$$
y_{i t}=X_{i t} \beta_{t}+\epsilon_{i t}
$$

Here $y_{i t}$ is $\log$ (weekly pay) and $\mathrm{X}$ is a full set of cohort and year indicators. As these subsume age indicators, $\mathrm{X}$ controls for predictable life cycle effects on earnings as well as aggregate shocks that differ across years. The error term, $\epsilon$, then reflects that part of earnings that is not systematically related to cohort, age, or year. We take a particular year and then keep all observations in the 5-year window centred on it. So, for example, for 1985, we keep observations from 1983 to 1987 . We then estimate the regression above on these data and, for each individual, we calculate the standard deviation of their earnings residual over this 5 -year period ${ }^{6}$ This procedure gives us a measure of earnings variability for each individual for the middle year of each 5-year period and allows us to estimate the effect of education on earnings variability at each age.7

In practice, for various reasons, it is not the case that every person is in our sample in

\footnotetext{
${ }^{6}$ An alternative to this approach would be to estimate the parameters of an earnings process and use it to estimate the variances of transitory and permanent components. Our approach has the advantage of not relying on the specification of some arbitrary parametric form for the earnings process.

${ }^{7}$ We do not attempt to identify how much of the variability is known in advance. There has been a series of papers in the literature attempting to address this issue - separating what is known in advance from what is actual uncertainty using, for example, information on education choices (Cunha et al. (2005)) and consumption (Blundell et al. (2008)). We do not have data on either of these variables and therefore we do not attempt to identify how much of the variability is known in advance. As a result,
} 
every year of each rolling 5-year panel. Therefore, we face a trade-off in that, if we require people to have valid earnings observations in all 5 years, we will have a much reduced sample size and a quite selected sample. However, if we estimate the standard deviation in all feasible cases (i.e. where there are at least 2 observations on the individual), some standard deviations will be much more precisely estimated than others. In practice, we have taken a compromise position of requiring a valid earnings observation for at least 4 years out of the 5 although we show later that the results are robust to restricting the sample to those with at least 2,3 , or 5 observations $8^{8}$

Earnings Cyclicality: The extent to which earnings move in line with the business cycle is another important measure of earnings volatility. There is a large literature that studies the relationship between education and the degree of wage cyclicality but none of these papers attempt to estimate the causal effect of education.9 The papers usually estimate regressions with a wage variable as the dependent variable and some business cycle proxy such as the unemployment rate as a right-hand side regressor and either look separately by education group or interact the unemployment rate with education. However, persons with different levels of education may also differ in other unobserved ways that affect wage cyclicality.

Our first measure of the business cycle is the UK unemployment rate in April of the survey year (the NESPD survey takes place in April). The basic idea is to first estimate the earnings cyclicality coefficient for each cohort and then to treat the earnings cyclicality of the cohort as the dependent variable in the second cohort-level step. We obtain the we interpret our variability measure as representing an upper bound on the amount of uncertainty faced by an individual over the 5-year period.

${ }^{8}$ Also, in Section 6, we find no evidence for a relationship between law exposure and having an earnings variability observation in our sample.

${ }^{9}$ The literature looking at the effects of wage cyclicality across education groups finds mixed results. Bils (1985) and Keane and Prasad (1991) and Solon et al. (1994) find no difference in wage cyclicality across education groups. However, Hines et al. (2001) and Hoynes et al. (2012) find that the low educated are most sensitive to business cycles while Ammermueller et al. (2009) find the opposite. Recently, Blundell et al. (2014) show that between 2009 and 2012 real wages decreased by about 10 percent for all education groups in the UK. 
cyclical coefficients for each cohort by estimating the following regression for each cohort, c, separately.

$$
\Delta y_{i t}=\alpha_{0 c}+\alpha_{1 c} \Delta u_{t}+\alpha_{2 c} y e a r+\epsilon_{i t}
$$

Here $\Delta y$ denotes the change in log earnings and $\Delta u$ denotes the change in the aggregate unemployment rate while controlling for year allows for a linear trend in earnings growth 10 We use the estimated coefficient from each cohort-specific regression $\hat{\alpha}_{1 c}$, as our measure of the earnings cyclicality experienced by cohort c.

To allow for more variation in unemployment rates we add to our aggregate analysis by also exploiting variation in regional unemployment rates. We use the 12 standard statistical regions used for the UK. The empirical analysis follows exactly as before except we add region dummies in the first step and use the regional unemployment rate rather than the national unemployment rate. Here $\mathrm{r}$ denotes region.

$$
\Delta y_{i t}=\alpha_{0 c}+\alpha_{1 c} \Delta u_{t r}+\alpha_{2 c} \text { year }+ \text { region }_{r}+\epsilon_{i t}
$$

Figure 1 shows the unemployment rates in each region over the sample period. While the unemployment rates tend to move in unison, there is some divergence in unemployment rates between regions ${ }^{11}$ Again, we use the estimated coefficient from each cohort-specific regression $\hat{\alpha}_{1 c}$, as our measure of the earnings cyclicality experienced by cohort $\mathrm{c}$.

Pay Cuts: We use the prevalence of pay cuts as an additional measure of earnings volatility. Earnings generally rise over the life cycle so pay cuts are likely to be unexpected and unpleasant for workers. Nickell et al. (2002) use occupation coding to assign workers to skill groups and find that low skilled workers are more likely to experience nominal

\footnotetext{
${ }^{10} \mathrm{By}$ taking the difference in log earnings we increase the robustness of our estimates by differencing out unobserved heterogeneity that is fixed over time. This specification is fairly standard in the wage cyclicality literature and is used, for example, by Solon et al. (1994)

${ }^{11}$ We have also looked at estimates whereby we add year dummies to the first step to allow us to control for year effects so that we are only left with the variation in unemployment rates that is derived uniquely from variation across regions and abstracts from any national business cycles. However, due to the fact that the regional rates are so highly correlated, the standard errors become very large and the estimates are not informative.
} 


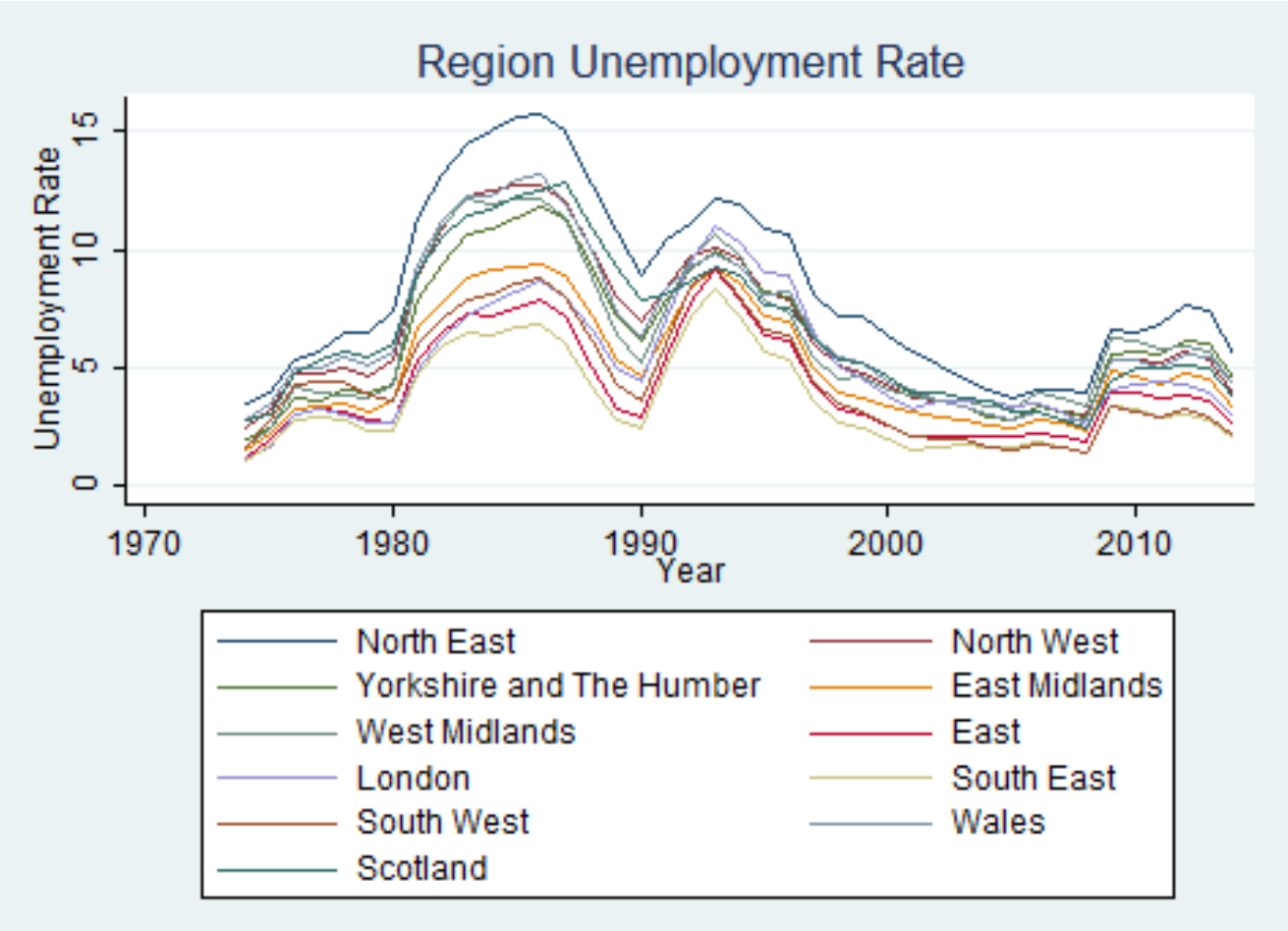

Figure 1: Regional Unemployment Rates

pay cuts. But, again, we are unaware of analysis in the literature of the causal effects of education on the probability of a pay cut. These issues have become particularly relevant in the recent 'Great Recession' due to the large number of both real and nominal pay cuts. In keeping with our analysis of standard deviations, we measure pay cuts as occurring if the real weekly pay of a worker is lower than he received 5 years previously. By studying cuts over a 5-year period, we reduce the number of cuts that occur due to extremely short-term changes and so should have less noise in our measure.

\section{Estimation Strategy}

In 1972 the UK government raised the minimum school leaving age from 15 to 16. This law affected all students in England, Wales, and Scotland born on or after September 1st 1957 and was a follow up to the first raising of the school leaving age (RoSLA) in 1947.12

\footnotetext{
${ }^{12}$ The relevant statutory instruments can be found at

http://www.legislation.gov.uk/uksi/1972/59/pdfs/uksi_19720059_en.pdf for Scotland and http://www.legislation.gov.uk/uksi/1972/444/pdfs/uksi_19720444_en.pdf for England and Wales.
} 
These laws have been much utilised in the literature to estimate the returns to additional years of education (Harmon and Walker (1995), Oreopoulos (2006), Devereux and Hart (2010), Grenet (2013), Clark and Royer (2013), Buscha and Dickson (2015), Dolton and Sandi (2017)). We use a regression discontinuity design that focuses on differences in outcomes of those born on either side of the cut-off.

Our primary approach is to estimate the model non-parametrically using a local linear regression with rectangular kernel weights (Hahn et al. (2001)).13 To focus on cohorts born close to the law change, we restrict the sample to cohorts born between 1952 and 1962 corresponding to 5 years on either side. However, we also show estimates where we use bigger bandwidths (cohorts born up to 10 years each side of the discontinuity) and other specifications such as a global polynomial approach, similar to Devereux and Hart (2010) and Oreopoulos (2006). One important issue with regression discontinuity designs is determining the best way to conduct inference. With cohort-based designs like ours, researchers often choose to cluster by cohort. However, this has been shown to be very unreliable if the number of clusters is small such as in our case where we have 10 cohorts in the local linear regressions. To avoid this issue we conduct all our analysis at the cohort level. First, we average each dependent variable by cohort and then we run the regressions at the level of the cohort means. As suggested by Dickens (1990) and Donald and Lang (2007), we do not weight by the number of observations in each cohort (weighted estimates are very similar) ${ }^{14}$

The NESPD dataset contains very accurate earnings data, has large sample sizes, and has repeated observations on individuals that allow us to construct individual measures of earnings volatility. However, it does not contain data on month of birth. Given persons born after September 1st 1957 were subject to the new compulsory schooling law, we use a 'donut' style approach whereby we omit the year 1957 from the estimation.

\footnotetext{
See, also, Barcellos et al. (2017) for details. Our sample includes men in all three regions.

${ }^{13}$ Imbens and Lemieux (2008) suggest using a simple rectangular kernel since using different weights only changes those estimates which are already sensitive to the bandwidth and thus are already invalid. Moreover, the asymptotic bias is independent of the choice of weights.

${ }^{14}$ This approach is conservative as it implies that our main regressions have only 10 observations.
} 
We focus on the reduced form relationship between the law and our outcome variables:

$$
Y_{i t}=\theta_{0}+\theta_{1} L_{a w_{i}}+f\left(Y O B_{i}\right)+u_{i t}
$$

Here Y refers to the dependent variable of interest and Law is an indicator variable denoting whether the individual was born before or after 1957. The function $\mathrm{f}($.$) represents$ a smooth function of year of birth. When we use local linear regression, this is a linear function of year of birth that is allowed to have different slopes on each side of the discontinuity. In other specifications $\mathrm{f}($.$) is proxied by a low order polynomial. We estimate$ this regression by survey year, so cohort is perfectly collinear with age. The YOB control allows for linear cohort/age effects and the effect of the law is identified by the presence of a discontinuity after the law change. Note that we do not control for labour market experience. People who stay in school longer will tend to have less labour market experience at any age but, in keeping with most of the causal literature, we treat this as part of the causal effect of obtaining more schooling.

The NESPD has no information on years of education. Given that the UK compulsory schooling laws have been so widely studied, we follow Buscha and Dickson (2015) and use 0.30 to 0.35 as our estimate of the first stage. This is due to the general consensus in the literature that the law increased years of schooling by about 0.30 to 0.35 for males. Therefore the results that we find using the NESPD can be multiplied by about 3 to provide the effect of an extra year of education on the outcome variable. As a robustness check we also calculated the first stage using the British Household Panel Survey (BHPS) and found a first stage effect of 0.332 with a standard error equal to 0.061 (see figure ?? in the Appendix for a visual representation). This is very similar to previous studies. The figure below shows the first stage effect of the compulsory schooling change on the proportion leaving school at age 15 using the BHPS 15

\footnotetext{
${ }^{15}$ In the appendix, we show a similar figure but with age left school on the y-axis.
} 


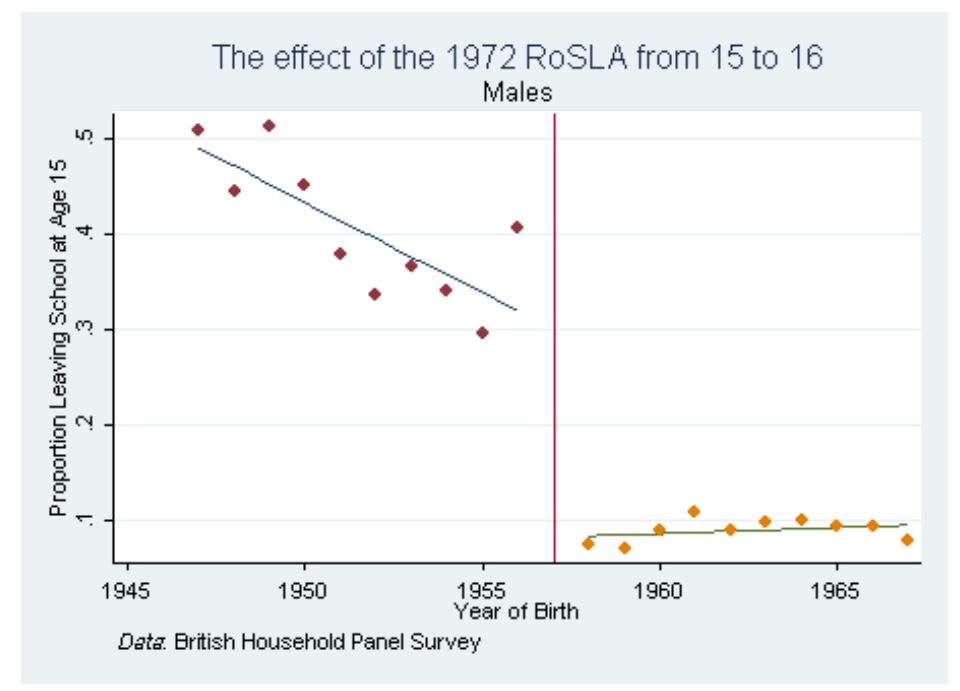

Figure 2: Effect of the Law on the Proportion Leaving School at Age 15

The large first stage effect implies that the law change affected a sizeable proportion of the population. Other evidence also suggests that affected men were fairly "typical" in terms of earnings. Men in our cohorts who left school at age 16, have median earnings that are at the 44th percentile of the overall male weekly earnings distribution and about $40 \%$ have above median earnings (authors' calculations using the Quarterly Labour Force Survey).

\section{Results}

\subsection{Log Weekly Pay}

While our interest is in earnings volatility rather than in the level of earnings, we provide some context by first showing the effects of the reform on log weekly pay. Recent research (Bhuller et al. (2017), Buscha and Dickson (2015)) has emphasised the importance of variation in the return to education over the life cycle. Table 2 reports estimates by year and thus tracks out returns over the life cycle. For example, the first estimate is for 1983 when the 1957 cohort is aged 25 (and the 1952-1962 cohorts used in estimation are aged between 20 and 30). The final estimate is for 2013 at which point the 1957 cohort is aged 55 and the cohorts used in estimation are aged between 50 and 60. The estimates suggest returns to reform exposure of about $4 \%$ at around age 35 and returns of about 
$2 \%$ at younger ages. Evidence for positive returns is weak for men over age 40 and the coefficient is even negative in a few of the later years. ${ }^{16}$

In Table 2 we also show results where we pool across ages. First, we take average $\log$ (weekly pay) across all years for each cohort and then use it as the dependent variable. The resultant coefficient of 0.018 is not statistically significant but implies a return to an extra year of education of about $6 \%$. This is similar to what other researchers have found for this law change using other data sets (Grenet (2013), Dickson (2012)). ${ }^{17}$ We also split the sample in two into a younger group (when the 1957 cohort is aged 25 to 39) and an older group (when the 1957 cohort is aged 40 to 55) and report separate estimates for these two groups. Consistent with the life cycle patterns, the point estimate is somewhat larger for the younger group. Figures $3-5$ provide a visual impression of these estimates by plotting out average $\log$ (weekly pay) by cohort. There is a clear pattern of earnings falling with cohort for younger men. This presumably arises because they are on the upward sloping part of their life cycle earnings profile.

It is important to note that while our sample gets older as we move to later survey years, we cannot be sure that differences in estimates by age are true effects of ageing. This is because the return to education could change across time even if the average age of sample members was time invariant. One possible reason is secular changes in the return to education that might arise because of technological change. Another is cyclical effects that could arise if education influences how earnings respond to the business cycle. We examine this directly later in the paper.

\footnotetext{
${ }^{16}$ While many studies have shown life cycle relationships between education and earnings, we are only aware of two studies that show causal estimates by detailed age. Using a very different estimation method, Buscha and Dickson (2015) show a broadly similar pattern of increasing then decreasing returns using the NESPD. Our estimates are, however, in contrast to results from Norway which show that the returns are typically lower at the beginning of the life cycle and higher at the end (Bhuller et al. 2017). However, the authors note in their paper that these types of estimates are likely to vary across national and institutional settings.

${ }^{17}$ Grenet (2013) uses the Quarterly Labour Force Survey from 1993 to 2004 and finds a return of 6-7\% while Dickson (2012) using the British Household Panel Survey 1991 to 2006 finds a 10\% return.
} 
Table 2: Effect of the Law on Log Weekly Pay

\begin{tabular}{clcccc}
\hline \hline Year (age of 1957 cohort) & \multicolumn{2}{c}{ Effect } & Year (age of 1957 cohort) & \multicolumn{2}{c}{ Effect } \\
\hline $1983(25)$ & 0.0187 & $(0.0173)$ & $1999(41)$ & 0.0068 & $(0.0167)$ \\
$1984(26)$ & 0.0271 & $(0.0178)$ & $2000(42)$ & 0.0244 & $(0.0252)$ \\
$1985(27)$ & 0.0218 & $(0.0205)$ & $2001(43)$ & 0.0163 & $(0.0200)$ \\
$1986(28)$ & 0.0286 & $(0.0167)$ & $2002(44)$ & 0.0006 & $(0.0196)$ \\
$1987(29)$ & 0.0260 & $(0.0211)$ & $2003(45)$ & 0.0168 & $(0.0203)$ \\
$1988(30)$ & 0.0109 & $(0.0226)$ & $2004(46)$ & 0.0050 & $(0.0226)$ \\
$1989(31)$ & 0.0289 & $(0.0166)$ & $2005(47)$ & 0.0226 & $(0.0254)$ \\
$1990(32)$ & 0.0300 & $(0.0178)$ & $2006(48)$ & 0.0230 & $(0.0233)$ \\
$1991(33)$ & $0.0356^{*}$ & $(0.0179)$ & $2007(49)$ & 0.0372 & $(0.0218)$ \\
$1992(34)$ & $0.0466^{* * *}$ & $(0.0111)$ & $2008(50)$ & 0.0246 & $(0.0276)$ \\
$1993(35)$ & $0.0462^{*}$ & $(0.0198)$ & $2009(51)$ & 0.0324 & $(0.0187)$ \\
$1994(36)$ & $0.0424^{* *}$ & $(0.0144)$ & $2010(52)$ & -0.0142 & $(0.0131)$ \\
$1995(37)$ & $0.0276^{*}$ & $(0.0136)$ & $2011(53)$ & 0.0103 & $(0.0176)$ \\
$1996(38)$ & 0.0212 & $(0.0166)$ & $2012(54)$ & 0.0053 & $(0.0112)$ \\
$1997(39)$ & 0.0175 & $(0.0096)$ & $2013(55)$ & -0.0114 & $(0.0206)$ \\
$1998(40)$ & -0.0032 & $(0.0179)$ & & & \\
\hline \hline Young (aged less than 40$)$ & $0.0252^{*}$ & $(0.0122)$ & $\mathrm{n}=302,527$ & $\bar{Y}=6.24$ & \\
Older (aged 40+) & 0.0141 & $(0.0154)$ & $\mathrm{n}=271,971$ & $\bar{Y}=6.45$ & \\
\hline & 0.0180 & $(0.0118)$ & $\mathrm{n}=574,498$ & $\bar{Y}=6.34$ & \\
\hline
\end{tabular}

All regressions done at the cohort level. Standard errors in parentheses. Significance level: ${ }^{* * *}$ at $.01, * *$ at .05 and $*$ at $.10 . \bar{Y}$ refers to the sample mean of the dependent variable.

\subsection{Earnings Variability}

Table 3 shows the effects of the law on the standard deviation of earnings over the life cycle. Because, we can only estimate this for the middle year in each rolling 5-year period, we have estimates by year from 1985 to 2011 . What is immediately clear from the table is that most of the effect of the law on earnings variability happens at young ages with law exposure leading to less variability. There are large effects of the law around age 27-32 in the range of about 0.01. The average standard deviation for the 1957 cohort in this age range is 0.15 . Therefore, a coefficient of -0.01 implies about a $7 \%$ reduction. 
Given an effect of the law change on education of about 0.30 to 0.35 , this implies that an extra year of education decreases earnings volatility by around 0.03 or by about $20 \%$ of the mean which is quite a large effect. However, the size of the effect gets smaller as men age and many of the point estimates even become positive (albeit statistically insignificant) as men approach their 50s. One interpretation of this pattern is that more education helps people to find better and more stable job matches in their early career but the effect becomes unimportant at older ages when most individuals have found suitable job matches. Of course, as mentioned earlier, an alternative possibility is that these are time rather than age effects and that education particularly sheltered workers during the 1985-1990 period. While we can't rule out this possibility, the general pattern seems more consistent with an age rather than a cyclical effect.

As in Table 2, we also report estimates where we increase precision by pooling across age groups. We find a statistically significant effect of -0.0065 for men aged less than 40 but no evidence of any effect for older men. We can assess whether these estimates are statistically different using a Hausman test: Under the null hypothesis that there is no difference between young and old, using the full sample provides a consistent and efficient estimator for the young (or old) while, under the alternative hypothesis, it gives inconsistent estimates for each individual group. Using this test, we find that the young and old estimates are statistically different at the $10 \%$ level. Over the entire life cycle, the average effect is -0.0042 but this estimate is not statistically significant.

Figures 6 - 8 provide a visual impression of these estimates. While the discontinuity is obvious for younger men, there is no obvious jump in the older sample. Note that there is a clear pattern of earnings variability rising with cohort for younger men, presumably because earnings variability falls with age as workers become more settled into the labour market. 
Table 3: Effect of the Law on the Standard Deviation of Log Earnings

\begin{tabular}{cllcll}
\hline \hline Year (age of 1957 cohort) & \multicolumn{2}{c}{ Effect } & Year (age of 1957 cohort) & \multicolumn{2}{c}{ Effect } \\
\hline $1985(27)$ & $-0.0110^{* * *}$ & $(0.0029)$ & $1999(41)$ & -0.0057 & $(0.0050)$ \\
$1986(28)$ & -0.0118 & $(0.0066)$ & $2000(42)$ & $-0.0069^{* * *}$ & $(0.0019)$ \\
$1987(29)$ & -0.0081 & $(0.0056)$ & $2001(43)$ & -0.0044 & $(0.0057)$ \\
$1988(30)$ & $-0.0111^{* * *}$ & $(0.0024)$ & $2002(44)$ & -0.0045 & $(0.0050)$ \\
$1989(31)$ & $-0.0101^{* * *}$ & $(0.0025)$ & $2003(45)$ & -0.0001 & $(0.0057)$ \\
$1990(32)$ & -0.0067 & $(0.0055)$ & $2004(46)$ & 0.0033 & $(0.0059)$ \\
$1991(33)$ & -0.0050 & $(0.0034)$ & $2005(47)$ & 0.0009 & $(0.0070)$ \\
$1992(34)$ & -0.0014 & $(0.0057)$ & $2006(48)$ & -0.0037 & $(0.0053)$ \\
$1993(35)$ & -0.0042 & $(0.0062)$ & $2007(49)$ & -0.0088 & $(0.0060)$ \\
$1994(36)$ & -0.0049 & $(0.0040)$ & $2008(50)$ & -0.0015 & $(0.0039)$ \\
$1995(37)$ & -0.0047 & $(0.0047)$ & $2009(51)$ & -0.0008 & $(0.0066)$ \\
$1996(38)$ & -0.0060 & $(0.0034)$ & $2010(52)$ & 0.0033 & $(0.0073)$ \\
$1997(39)$ & -0.0045 & $(0.0034)$ & $2011(53)$ & 0.0064 & $(0.0048)$ \\
$1998(40)$ & -0.0062 & $(0.0044)$ & & & \\
\hline \hline Young (aged less than 40) & $-0.0065 * *$ & $(0.0026)$ & $\mathrm{n}=197,741$ & $\bar{Y}=0.142$ & \\
Older (aged 40+) & -0.0022 & $(0.0027)$ & $\mathrm{n}=175,943$ & $\bar{Y}=0.122$ & \\
All & -0.0042 & $(0.0025)$ & $\mathrm{n}=373,684$ & $\bar{Y}=0.132$ & \\
\hline
\end{tabular}

Standard deviations measured in the 5-year period centred around the listed year with at least 4 observations per window. Local linear regression estimates using cohorts born between 1952 and 1962 with the 1957 cohort omitted. All regressions done at the cohort level. Standard errors in parentheses. Significance level: ${ }^{* * *}$ at $.01,{ }^{* *}$ at .05 and ${ }^{*}$ at $.10 . \bar{Y}$ refers to the sample mean of the dependent variable.

In the estimates so far, we require at least 4 wage observations per person in each 5-year window. In Table 4, we examine whether the estimates are sensitive to using different requirements. First, looking at the sample sizes, we see that as we move from the least restrictive (only requiring 2 observations) to the most restrictive (requiring all $5)$, we lose over half the person-year observations. However, the estimates are quite robust - the effect of the law on the younger group varies between -0.0063 and -0.0071 and is always statistically significant. Likewise, there is never any evidence of an effect on the older group. 
Table 4: Effect of the Law on the Standard Deviation of Earnings

\begin{tabular}{ccccc}
\hline \hline & \multicolumn{2}{c}{ Effect } & Sample Size & Sample Mean \\
\hline $\begin{array}{c}\text { SD calculated using at least 2 obs } \\
\text { Young }\end{array}$ & $-0.0064^{* *}$ & $(0.0026)$ & 255,679 & 0.1467 \\
Old & -0.0018 & $(0.0028)$ & 235,281 & 0.1266 \\
All & -0.0041 & $(0.0025)$ & 490,960 & 0.1371 \\
SD calculated using at least 3 obs & & & & \\
Young & $-0.0063^{* *}$ & $(0.0026)$ & 238,787 & 0.1446 \\
Old & -0.0021 & $(0.0024)$ & 218,468 & 0.1245 \\
All & -0.0040 & $(0.0024)$ & 457,255 & 0.1350 \\
SD calculated using at least 4 obs & & & & \\
Young & $-0.0065^{* *}$ & $(0.0026)$ & 197,741 & 0.1416 \\
Old & -0.0022 & $(0.0027)$ & 175,943 & 0.1221 \\
All & -0.0042 & $(0.0025)$ & 373,684 & 0.1325 \\
SD calculated using at least 5 obs & & & & \\
Young & $-0.0071^{*}$ & $(0.0031)$ & 126,388 & 0.1343 \\
Old & 0.0010 & $(0.0024)$ & 111,500 & 0.1144 \\
All & -0.0031 & $(0.0026)$ & 237,888 & 0.1250 \\
\hline
\end{tabular}

All regressions done at the cohort level. Standard deviations measured in the 5-year period centred around the listed year. Local linear regression estimates using cohorts born between 1952 and 1962 with the 1957 cohort omitted. Standard errors in parentheses. Significance level: ${ }^{* * *}$ at .01, ${ }^{* *}$ at .05 and $*$ at .10 . 


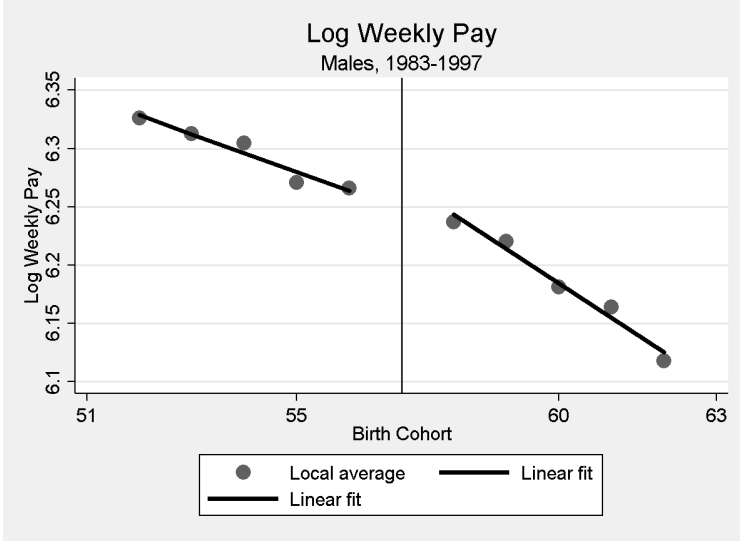

Figure 3: Log Weekly Pay, Young

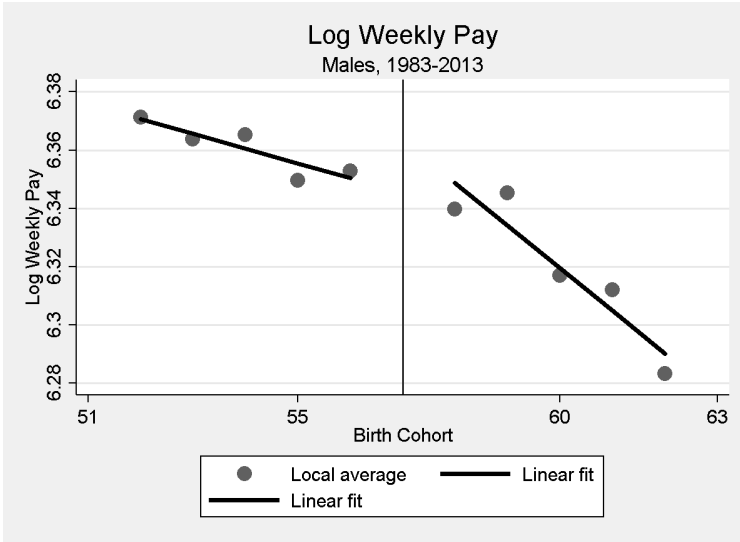

Figure 5: Log Weekly Pay, All

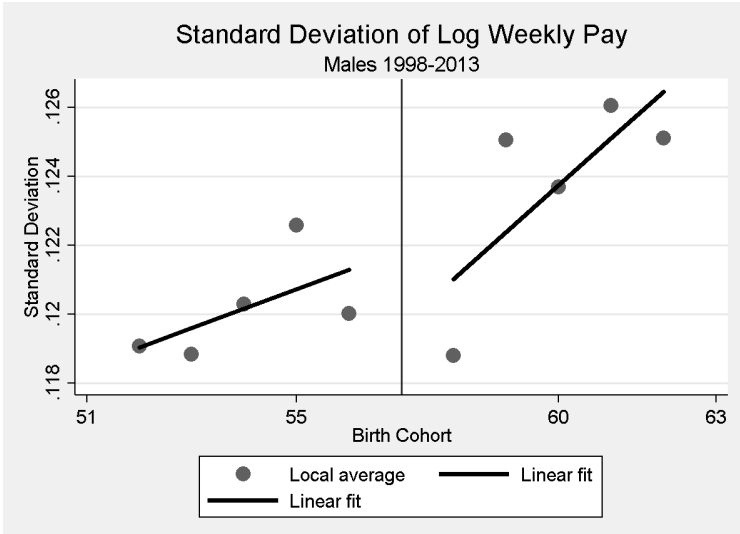

Figure 7: Standard Deviation, Old

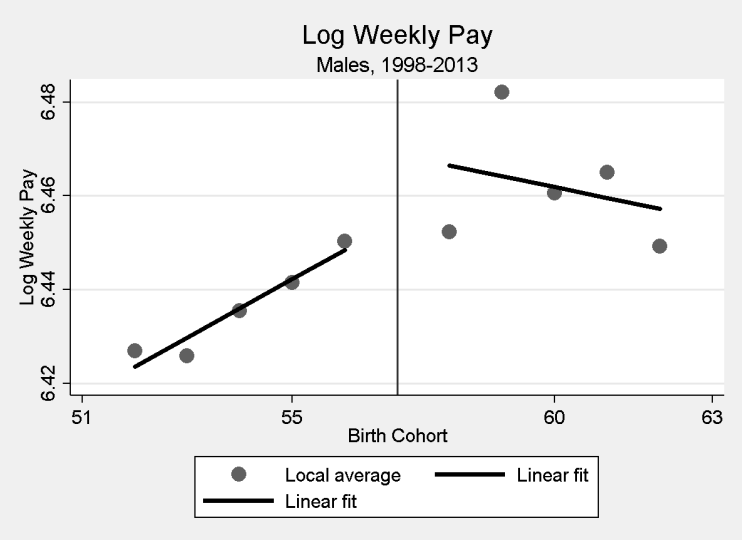

Figure 4: Log Weekly Pay, Old

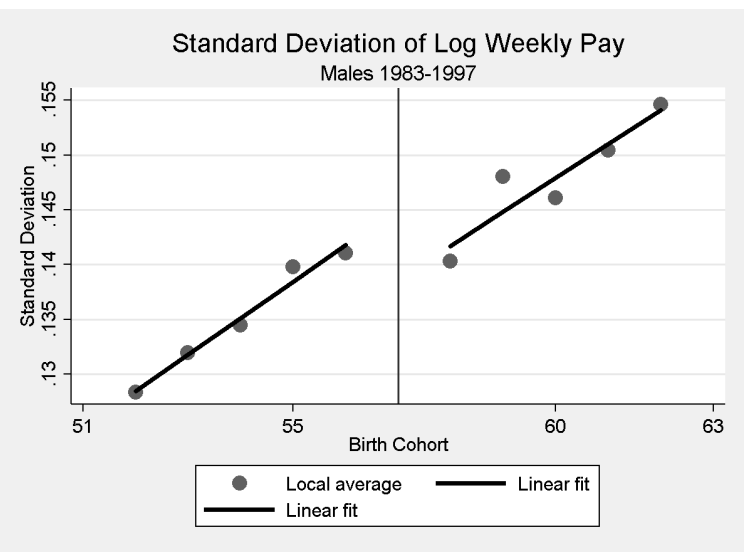

Figure 6: Standard Deviation, Young

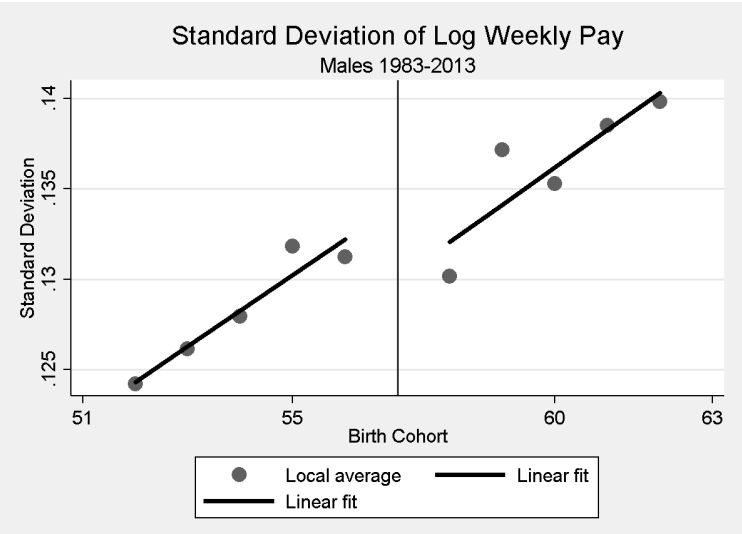

Figure 8: Standard Deviation, All 


\subsection{Earnings Cyclicality}

As mentioned earlier, we calculate an earnings cyclicality coefficient for each cohort. To estimate the effect of the law on earnings cyclicality, we do a cohort-level regression where we regress the cyclicality coefficient for each cohort on the law using the local linear specification. The estimates are reported in Table 5.

Because we need a large time dimension to reliably estimate the earnings cyclicality coefficients, we cannot study how the effect of the law on earnings cyclicality varies at each individual age. We report estimates for the full set of years (1983-2013) and also split the sample by age group (younger versus older) as before. In practice, we estimate earnings cyclicality over the 1983-1997 period when studying the younger group and the 1998-2013 period for the older group. However, the standard errors are very high for the older group so this estimate is not very informative. In Table 5 we see that the effect of the law on earnings cyclicality is about 0.0039 overall and, similarly, about 0.0044 for the younger group. Both these estimates are large and very statistically significant. The positive coefficient implies that law exposure reduces the negative relationship between changes in earnings and changes in the unemployment rate.

Table 5: Effect of the Law on Earnings Cyclicality

\begin{tabular}{ccccc}
\hline \hline Sample & \multicolumn{2}{c}{ Effect } & Sample Size & Sample Mean \\
\hline Young (aged less than 40) & $0.0044^{* * *}$ & $(0.0008)$ & 223,974 & -0.0037 \\
Older (40+) & 0.0005 & $(0.0054)$ & 202,412 & 0.0123 \\
All & $0.0039^{* * *}$ & $(0.0008)$ & 441,890 & -0.0012 \\
\hline
\end{tabular}

Local linear regression estimates using cohorts born between 1952 and 1962 with the 1957 cohort omitted. All regressions done at the cohort level. Standard errors in parentheses. Significance level: $* * *$ at $.01,{ }^{* *}$ at .05 and ${ }^{*}$ at .10 .

To get a sense of the magnitudes, it is helpful to look at Figures 9 - 11. The pictures show the estimated earnings cyclicality coefficient by cohort. For young men, this is always negative, reflecting the fact that earnings are mildly procyclical with estimates ranging from close to zero to -0.007 . These suggest that a one point increase in the 
unemployment rate reduces earnings by between 0 and $0.7 \%$ and indicate considerably larger cyclical sensitivity for later cohorts. For the full sample, the divergence across cohort is smaller at between about 0 to -0.003 . The greater procyclicality experienced by those born in the early-to-mid 1960s may result from the fact that they were relatively young during the turbulent decade of the 1980s and younger workers are more sensitive to cyclical shocks ${ }^{18}$ However, it is difficult to establish a precise reason for the cohort trends using our data. There is a clear jump for the 1958 cohort with the levels of cyclicality being lower (in absolute terms) after the law change than before.

\subsubsection{Regional Shocks}

Table 6: Effect of the Law on Regional Earnings Cyclicality

\begin{tabular}{ccccc}
\hline \hline Sample & \multicolumn{2}{c}{ Effect } & Sample Size & Sample Mean \\
\hline Young (aged less than 40) & $0.0038^{* * *}$ & $(0.0007)$ & 223,974 & -0.0039 \\
Older (40+) & 0.0010 & $(0.0052)$ & 202,412 & 0.0107 \\
All & $0.0034^{* *}$ & $(0.0010)$ & 441,890 & -0.0013 \\
\hline
\end{tabular}

The cyclical indicator is the contemporaneous regional unemployment rate for April. All regressions done at the cohort level. Standard errors in parentheses. Significance level: *** at .01, ** at .05 and * at .10.

Table 6 shows the regional cyclicality estimates. The results are similar to the estimates using the national unemployment rate both in terms of the coefficient estimates and standard errors. This is not surprising since Figure 1 highlights that unemployment rates tend to move in parallel across regions. However, it is reassuring that, once we look within region and so control for any regional effects, the negative effect of the law change on earnings cyclicality remains.

\footnotetext{
${ }^{18}$ Much research has found that younger people are more sensitive to the business cycle, for example, Hoynes et al. (2012) and Elsby et al. (2010).
} 


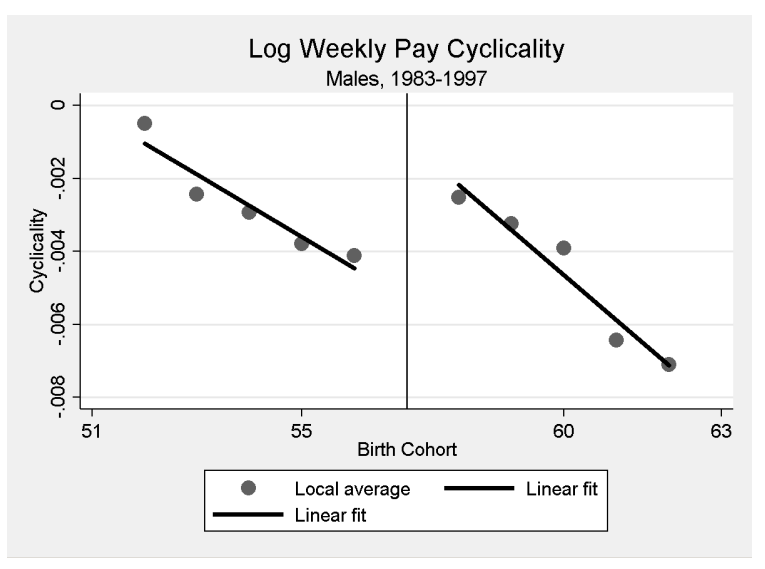

Figure 9: Cyclicality, Young

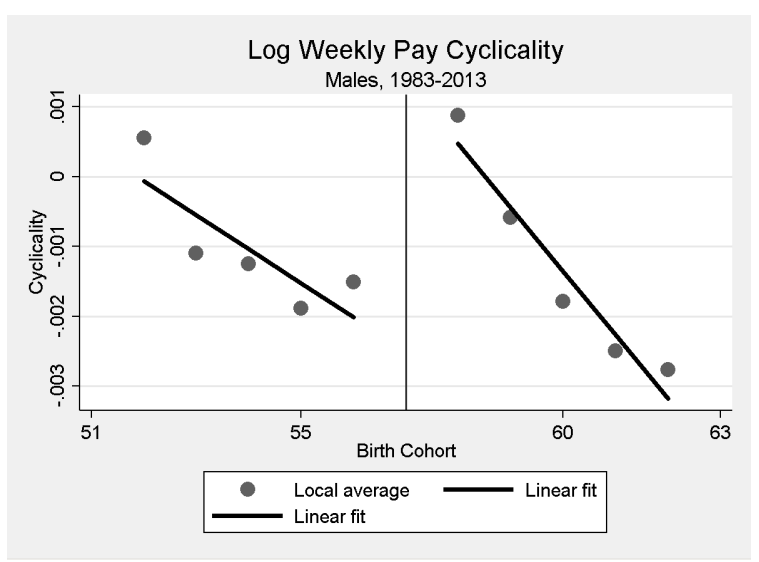

Figure 11: Cyclicality, All

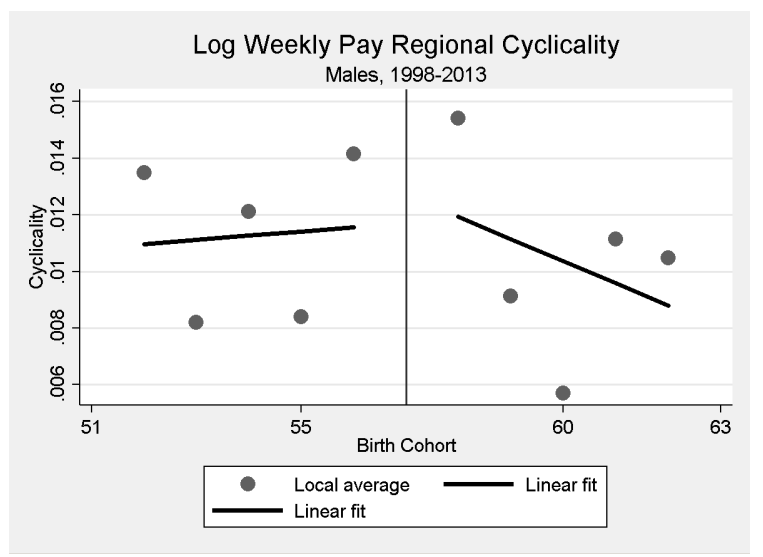

Figure 13: Regional Cyclicality, Old

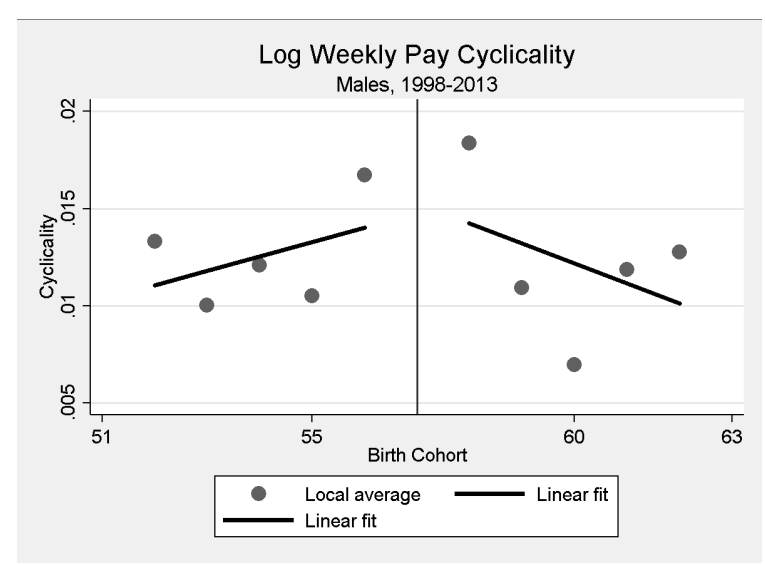

Figure 10: Cyclicality, Old

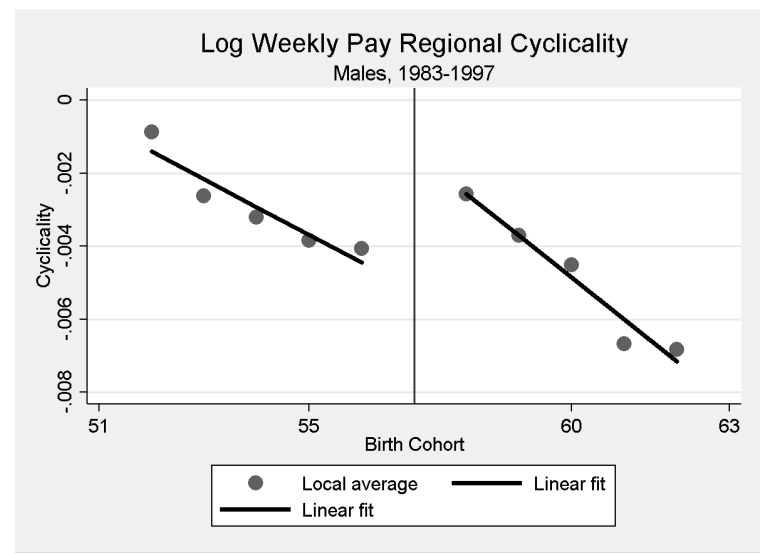

Figure 12: Regional Cyclicality, Young

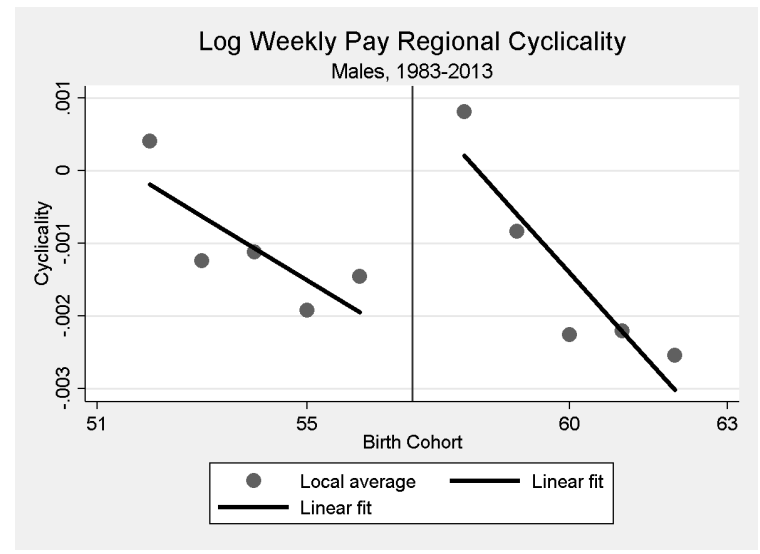

Figure 14: Regional Cyclicality, All 


\subsection{Pay Cuts}

Table 7 shows the effect of the law on the probability of a real pay cut in each 5-year period centred on the reported year. We define the pay cut variable to be equal to 1 if the real weekly pay at the end of the 5 -year period is less than what it was at the beginning of the period. So, for example, for the year 1987 in Table 7, the estimate shows the effect of law exposure on the probability that the real weekly pay in 1989 is lower than that in 1985. There is no clear pattern in the results with law exposure leading to a lower probability of receiving a cut in some years, for example, in 1989, 1992 and 2004 but at other times leading to an increased likelihood of a pay cut. The effect of education on lowering the probability of receiving a pay cut in 1992 is consistent with the fact that the 1990's recession had large adverse effects on those with the least education. It is not clear why the effects in 2004 are so large but it is something that we think deserves further investigation. The increased probability of the higher educated receiving a pay cut between 2007 and 2011 (as shown by the 2009 estimate) is consistent with evidence that the 'Great Recession' had a bigger impact on those with more education, in particular bankers and those working in the financial industry. ${ }^{19}$

Overall the effect of the law is to reduce the probability of a pay cut by 1.09 percentage points. The average probability of a pay cut for the 1957 cohort over the sample period is 0.342 . Therefore, a coefficient of -0.0109 implies about a $3.2 \%$ reduction. This implies that an extra year of education reduces the probability of receiving a pay cut by about 9 percent. However, it is important to keep in mind that there is a lot of heterogeneity across years with positive coefficients in some years and negative ones in others so the average effects over the entire period should be treated with caution. Figures $15-17$ show the estimates graphically.

\footnotetext{
${ }^{19}$ This is not surprising given that in 2009 financial institutions reacted to the Lehman Brothers' collapse by cutting pay.
} 
Table 7: Effect of the Law on the Probability of a Real Weekly Pay Cut (over 5-Year Period)

\begin{tabular}{cccccc}
\hline \hline Year (age of 1957 cohort) & \multicolumn{2}{c}{ Effect } & Year (age of 1957 cohort) & \multicolumn{2}{c}{ Effect } \\
\hline $1985(27)$ & -0.0150 & $(0.0109)$ & $1999(41)$ & -0.0210 & $(0.0121)$ \\
$1986(28)$ & -0.0260 & $(0.0133)$ & $2000(42)$ & -0.0236 & $(0.0218)$ \\
$1987(29)$ & 0.0001 & $(0.0169)$ & $2001(43)$ & 0.0010 & $(0.0195)$ \\
$1988(30)$ & -0.0122 & $(0.0103)$ & $2002(44)$ & 0.0087 & $(0.0150)$ \\
$1989(31)$ & $-0.0195^{*}$ & $(0.0096)$ & $2003(45)$ & -0.0176 & $(0.0288)$ \\
$1990(32)$ & -0.0288 & $(0.0216)$ & $2004(46)$ & $-0.0616^{* * *}$ & $(0.0162)$ \\
$1991(33)$ & 0.0001 & $(0.0158)$ & $2005(47)$ & -0.0111 & $(0.0202)$ \\
$1992(34)$ & $-0.0299^{*}$ & $(0.0143)$ & $2006(48)$ & -0.0451 & $(0.0330)$ \\
$1993(35)$ & -0.0049 & $(0.0152)$ & $2007(49)$ & -0.0071 & $(0.0176)$ \\
$1994(36)$ & $0.0171^{*}$ & $(0.0076)$ & $2008(50)$ & -0.0000 & $(0.0155)$ \\
$1995(37)$ & $0.0381^{*}$ & $(0.0181)$ & $2009(51)$ & $0.0447^{*}$ & $(0.0191)$ \\
$1996(38)$ & 0.0259 & $(0.0221)$ & $2010(52)$ & 0.0279 & $(0.0207)$ \\
$1997(39)$ & -0.0118 & $(0.0100)$ & $2011(53)$ & 0.0180 & $(0.0149)$ \\
$1998(40)$ & -0.0074 & $(0.0164)$ & & & \\
\hline \hline Young (aged less than 40) & $-0.0081^{*}$ & $(0.0037)$ & $\mathrm{n}=157,710$ & $\bar{Y}=0.260$ & \\
Older (aged 40+) & -0.0093 & $(0.0065)$ & $\mathrm{n}=195,484$ & $\bar{Y}=0.407$ & \\
All & $-0.0109^{*}$ & $(0.0046)$ & $\mathrm{n}=353,194$ & $\bar{Y}=0.342$ & \\
\hline
\end{tabular}

Local linear regression estimates using cohorts born between 1952 and 1962 with the 1957 cohort omitted. All regressions done at the cohort level. Standard errors in parentheses. Significance level: *** at .01, ** at .05 and $*$ at $.10 . \bar{Y}$ refers to the sample mean of the dependent variable. 


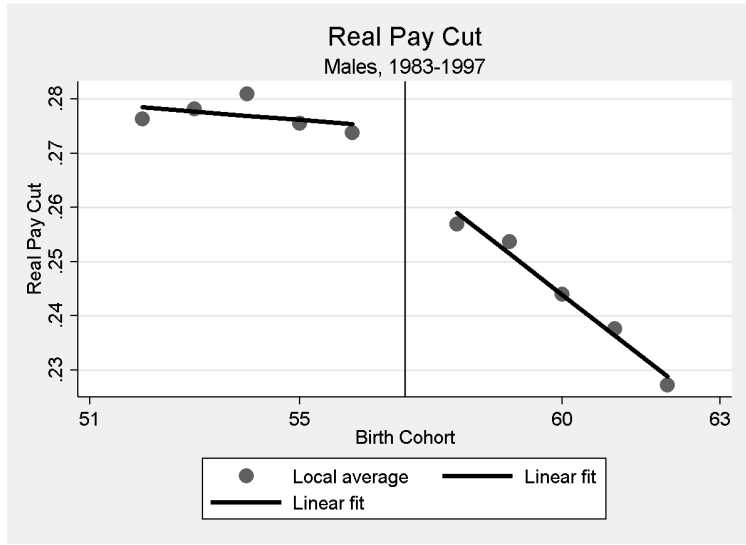

Figure 15: Probability of Pay Cut, Young

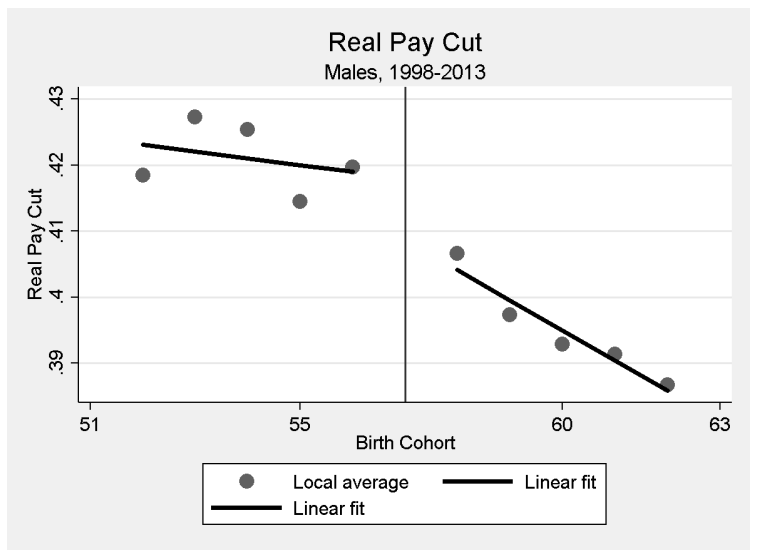

Figure 16: Probability of Pay Cut, Old

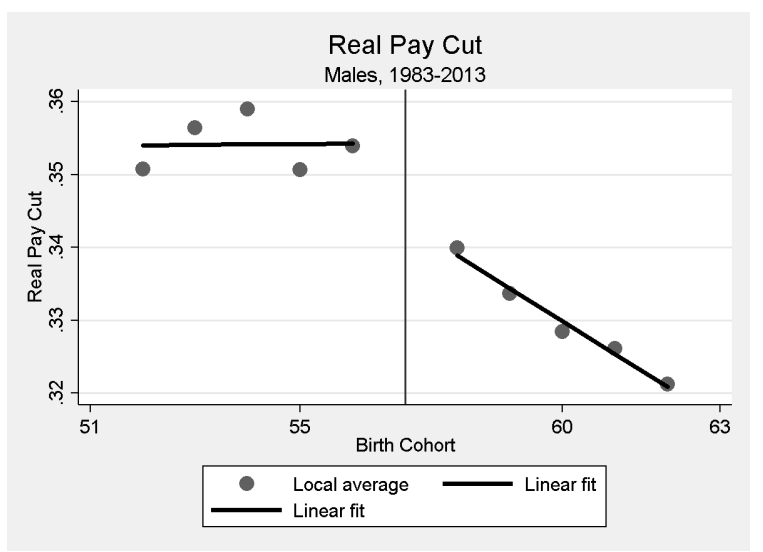

Figure 17: Probability of Pay Cut, All 


\section{Robustness Checks}

In this section, we perform some robustness checks for each of our outcome measures. The estimates are reported in the Appendix.

\subsection{Bandwidth and Model Specification}

First, we look at the effects of changing the bandwidth and the model specification. To compare with our baseline estimates that do local linear regression using a bandwidth of 5 , we examine the effect of bandwidths of 7 and 10 using a range of different specifications. Since the fit can vary greatly between specifications, we use the Akaike Information Criterion (AIC) to pick the model that fits best in each case. With the bandwidth of 5, the standard errors get very high when we use high order polynomials. Therefore, for this bandwidth, we only report a global quadratic in addition to the local linear specification. For bandwidths 7 and 10, we report local quadratic estimates that allow a different quadratic function each side of the discontinuity and also global quadratic, cubic, and quartic specifications. In each case, the estimate favoured by the AIC criterion is reported in bold.

The estimates are in Tables A1 to A5. In general, we find that, once one chooses the specification with the best fit for each bandwidth, the estimates are quite robust to specification. The estimates for the standard deviation, for earnings cyclicality, and (to a lesser extent) for pay cuts are all quite similar across bandwidths for the best-fitting model. We conclude that our findings are quite robust to the choice of bandwidth or specification.

Because persons born in 1957 may or may not have been subject to the new law, we have used a "donut" approach that involved excluding the 1957 cohort from the analysis. In Table A6 we take an alternative approach of setting the law variable equal to $1 / 3$ for the 1957 cohort. This reflects the fact that men born in September and after were affected and they constitute approximately $1 / 3$ of the cohort. We find that the estimates are quite similar using this specification. One exception is that the effect of the law on taking a real pay cut is no longer statistically significant. The lack of robustness of this result is perhaps unsurprising given the large variability in the estimates that we found 
for this variable across years.

As mentioned earlier in the paper, we have missing observations for each of the dependent variables because of non-employment, self-employment, and non-response. Here, we investigate whether the law can predict whether there is missing data on the dependent variables. We use the same local linear specification as for our main estimates. As can be seen in Table A7, we find that there is no evidence for any systematic relationship between the law and whether the dependent variables are missing. This finding is consistent with our earlier result that the estimates for the standard deviation are robust to variation in the number of required observations for each person over the five-year period. While this evidence cannot be definitive, it suggests that our estimates may not be biased by selection issues.

\subsection{Looking Beyond Weekly Earnings}

Our measure of weekly earnings depends both on average hourly earnings and weekly hours worked. Given that the log of weekly earnings equals the sum of the logs of each of these two variables, we look at the effect of the law change on each of these in turn. Note that weekly hours are reported by employers and reflect contracted hours including overtime hours. As shown in Table A8, we find very little evidence that hours variation is an important part of the story - exposure to the law has little effect on hours or our measures of hours variability. Indeed, the findings for the log hourly wage are fairly similar to those for weekly earnings, suggesting that the law mainly impacts weekly earnings through its effects on average hourly earnings.

From 1996, the NES has reported a measure of annual earnings with the current employer that encapsulates the 12-month period ending at the survey date in April. We use this variable for our "older" sample for the 1998-2013 period. We would expect the estimates to differ from those for weekly earnings if there is significant variation in hours worked over the year. In Table A9, we show estimates with this earnings measure along with estimates for weekly earnings for the exact same sample of men. The estimates are generally very similar and reinforce our earlier finding that the law appears to have little effect on the earnings variability of older men. 


\subsection{Standard Errors Clustered at the Individual Level}

We have conducted all our analysis at the cohort level. An alternative approach to inference is not to group by cohort but to instead treat deviation from the local linear or polynomial fit as specification error and report robust standard errors (Chamberlain, 1994). In situations where we pool years and so have repeated observations on individuals, we implement this method by clustering by individual. As a check on our earlier estimates, we report these standard errors in Tables A10 to A12. Given that earnings cyclicality is measured at the cohort level, it is not possible to generate standard errors at the individual level for this outcome. We find that the level of statistical significance is generally similar with this approach compared to our earlier approach. All our findings are robust to using this alternative method of inference.

\section{Conclusion}

We look at the effects of education on earnings volatility via the effects on earnings variability, earnings cyclicality, and frequency of real pay cuts of employed men. Across all three mechanisms, the results point towards benefits from education through sheltering men from the adverse effects of earnings shocks. We find that more education leads to lower earnings variability at younger ages but with no discernible benefits for persons aged over 40. We also find that more educated men are less affected by wage cyclicality. Our findings for real pay cuts are quite heterogeneous with the effects varying in magnitude and sign across different years. On average, however, more educated workers appear less likely to experience real pay cuts. The estimates are robust across many specifications. Overall, our paper identifies another, and largely unexplored, avenue through which education may lead to positive rewards in the labour market. 


\section{References}

Altonji, Joseph G. 1993. The demand for and return to education when education outcomes are uncertain. Journal of Labor Economics 11, no. 1:48-83.

Athreya, Kartik and Eberly, Janice C. 2015. The college premium, college noncompletion, and human capital investment. Working Paper No. 13-02R, Federal Reserve Bank of Richmond.

Ammermueller, Andreas., Anja. Kuckulenz and Thomas. Zwick. 2009. Aggregate unemployment decreases individual returns to education. Economics of Education Review $28: 217-226$.

Banks, James, Richard Blundell and Agar Brugiavini. 2001. Risk pooling, precautionary saving and consumption growth. Review of Economic Studies 68(4): 757-79.

Barcellos, Silvia, Leandro Carvalho and Patrick Turley. 2017. Genetic heterogeneity on the health returns to education. Working paper.

Bhuller, Manudeep., Magne Mogstad and Kjell G. Slavanes. 2017. Life Cycle Earnings, Education Premiums, and Internal Rates of Return. Journal of Labor Economics 35(4): 993-1030.

Bils, Mark J. 1985. Real wages over the business cycle: Evidence from panel data. Journal of Political Economy 93, 666-689.

Blundell, Richard, Luigi Pistaferri, and Ian Preston. 2008. Consumption inequality and partial insurance. American Economic Review 98(5): 1887-1921.

Blundell, Richard, Claire Crawford and Wenchao Jin. 2014. What can wages and employment tell us about the UK's productivity puzzle?. The Economic Journal 124, Issue 
$576,377-407$.

Blundell, Richard, Michael Graber and Magne Mogstad. 2015. Labor income dynamics and the insurance from taxes, transfers, and the family. Journal of Public Economics 127:58-73.

Buscha, Franz and Matt Dickson. 2015. The wage returns to education over the life cycle: Heterogeneity and the role of experience. Working Paper.

Chamberlain, G. 1994. Quantile regression, censoring, and the structure of wages. In: Sims, C.A. (Ed.), Advances in Econometrics, Sixth World Congress, vol. 1. Cambridge University Press, Cambridge.

Chen, Stacey. 2008. Estimating the variance of wages in the presence of selection and unobserved heterogeneity. Review of Economics and Statistics 90:2, 275-289.

Cunha, Flavio, James Heckman and Salvador Navarro. 2005. Separating uncertainty from heterogeneity in life cycle earnings. Oxford Economic Papers 57(2), 191-261.

Clark, Damon, and Heather Royer. 2013. The effect of education on adult mortality and health: evidence from Britain". American Economic Review 103(6): 2087-2120.

Delaney, Judith M. 2017. "To go to college or not? The role of ability, family background, and risk". Working Paper.

Devereux, Paul J. and Robert A. Hart. 2010. Forced to be rich? Returns to compulsory schooling in Britain. The Economic Journal 120.549: 1345-1364.

Dickens, William T. 1990. Error components in grouped data: Is it ever worth weighting?. The Review of Economics and Statistics 72, no. 2, 328-333. 
Dickson, M. 2013. The causal effect of education on wages revisited. Oxford Bulletin of Economics and Statistics 75: 477-498.

Dolton, Peter and Matteo Sandi. 2017. Returning to returns: revisiting the British education evidence. Labour Economics 48:87-104.

Donald, Stephen G., and Kevin Lang. 2007. Inference with difference-in-differences and other panel data. The Review of Economics and Statistics 89.2: 221-233.

Elsby, Michael W., Bart Hobijn and Aysegul Sahin. 2010. The labor market in the Great Recession. Published: Brookings Papers on Economic Activity, Economic Studies Program, The Brookings Institution, vol. 41(1 (Spring), pages 1-69.

French, Eric. 2005. The effects of health, wealth, and wages on labour supply and retirement behaviour. The Review of Economic Studies 72.2: 395-427.

Grenet, Julien. 2013. Is extending compulsory schooling alone enough to raise earnings? Evidence from French and British compulsory schooling laws. The Scandinavian Journal of Economics 115.1: 176-210.

Hahn, Jinyong., Petra Todd, and Wilbert. Van der Klaauw. 2001. Identification and estimation of treatment effects with a regression-discontinuity design. Econometrica 69(1): 201-209.

Harmon, Colm., and Ian Walker. 1995. Estimates of the Economic Return to Schooling for the United Kingdom. American Economic Review 85: 1278-1286.

Heathcote, Jonathan, Kjetil Storesletten, and Giovanni L. Violante. 2014. Consumption and labor supply with partial insurance: An analytical framework. American Economic 
Review 104(7): 2075-2126.

Hines, James. R., Hilary Hoynes and Alan. B Krueger. 2001. Another look at whether a rising tide lifts all boats. Working Paper no. 8412, National Bureau of Economic Research, Cambridge, MA.

Hoynes. Hilary, Douglas L. Miller, and Jessamyn Schaller. 2012. Who suffers during recessions?. Journal of Economic Perspectives 26(3): 27-48

Imbens, Guido W., and Thomas Lemieux. 2008. Regression discontinuity designs: A guide to practice. Journal of Econometrics 142.2: 615-635.

Ionescu, Felicia and Nicole Simpson. 2016. Default risk and private student loans: Implications for higher education policies. Journal of Economic Dynamics and Control 64(C): 119-147.

Johnson, Matthew T. 2013. Borrowing constraints, college enrollment and delayed entry. Journal of Labor Economics 31.4: 669-725.

Keane, Michael P., and Kenneth I. Wolpin. 1997. The career decisions of young men. Journal of Political Economy 105.3.

Keane, Michael, and Answar Prasad. 1993. Skill levels and the cyclical variability of employment, hours, and wages. International Monetary Fund Staff Papers 40, 711-743.

Liu, Kai, Magne Mogstad and Kjell Salvanes. 2015. Education, earnings dynamics, and life cycle inequality. Working Paper.

Low, Hamish, Costas Meghir, and Luigi Pistaferri. 2010. Wage risk and employment risk over the life cycle". American Economic Review, 100(4): 1432-67. 
Machin, Stephen., Kjell. G. Salvanes, and Panu. Pelkonen. 2012. Education and mobility. Journal of the European Economic Association 10: 417-450.

Meghir, Costas and Luigi Pistaferri. 2004. "Income variance dynamics and heterogeneity". Econometrica 72:1-32.

Mincer, Jacob. 1991. Education and unemployment. NBER Working Paper No 3838. National Bureau of Economic Research, Cambridge, MA.

Nickell, Stephen., Tracy Jones, and Glenda Quintini. 2002. A picture of job insecurity facing British men. The Economic Journal 112: 1-27.

Oreopoulos, Philip. 2006. Estimating average and local average treatment effects of education when compulsory schooling laws really matter. American Economic Review 96(1): 152-175.

Oreopoulos, Philip, and Kjell G. Salvanes. 2011. Priceless: The nonpecuniary benefits of schooling. Journal of Economic Perspectives 25(1): 159-84.

Solon, Gary., Robert Barsky, and Jonathan A. Parker. 1994. Measuring the cyclicality of real wages: How important is composition bias. The Quarterly Journal of Economics 109(1), 1-25. 